\title{
Need for treatment of gonorrhea to be effective against Chlamydia trachomatis
}

\author{
William R Bowie, MD, JoAnne Ast, RN, Linda Sibau, BSc, Carol Shaw, MSc, \\ HUGH D JONES, MD, WILLIAM A BLACK, MD
}

\begin{abstract}
WR BowIE, J Ast, L Sibau, C SHAw, HD JonEs, WA BLACK. Need for treatment of gonorrhea to be effective against Chlamydia trachomatis. Can J Infect Dis 1993;4(6):347-351. Men and women with gonorrhea or contact to gonorrhea are frequently co-infected with Chlamydia trachomatis. To assess the importance of using treatment regimens active against both Neisseria gonorrhoeae and C trachomatis, tetracycline 500 mg orally four times daily for five days, with activity against both organisms, was compared with ceftriaxone, $250 \mathrm{mg}$ once intramuscularly, with activity against only $N$ gonorrhoeae. $N$ gonorrhoeae microbiological failure occurred in six of 148 patients (4\%) on tetracycline and zero of 85 on ceftriaxone. Microbiological failure for $C$ trachomatis occurred in zero of 27 on tetracycline and 10 of $12(83 \%)$ on ceftriaxone $(\mathrm{P}<0.001)$. In addition, 14 others on ceftriaxone had $C$ trachomatis first isolated after treatment. When all types of microbiologialc and clinical failures are included, outcome was significantly better on tetracycline $(\mathrm{P}<0.001)$. Optimal treatment of patients with gonorrhea must include regimens with activity against both $C$ trachomatis and $N$ gonorrhoeae.
\end{abstract}

Key Words: Ceftriaxone, Chlamydia trachomatis, Gonorrhea, Neisseria gonorrhoeae, Tetracycline

\section{De la nécessité d'un traitement efficace contre la gonorrhée dans l'infection à Chlamydia trachomatis}

RÉSUMÉ: Les hommes et les femmes atteints de gonorrhée ou exposés à cette maladie sont fréquemment infectés à la fois par Chlamydia trachomatis. Pour mesurer l'importance de recourir à des schémas thérapeutiques efficaces tant contre Neisseria gonorrhoeae que contre $C$ trachomatis, la tétracycline 500 mg par voie orale quatre fois par jour durant cinq jours, active contre les deux organismes, a été comparée avec la ceftriaxone $250 \mathrm{mg}$ une fois par voie intramusculaire, active contre $N$ gonorrhoeae. Un échec thérapeutique a été constaté contre $N$ gonorrhoeae chez six des 148 patients $(4 \%)$ traités avec tétracycline et chez aucun des 85 patients à qui l'on administrait la ceftriaxone. L'échec thérapeutique contre $C$ trachomatis ne s'est produit chez aucun des 27 patients prenant de la tétracycline, et s'est produit chez 10 des 12 patients sous ceftriaxone (83\%) ( $\mathrm{P}<0,001)$. De plus, chez 14 autres patients sous ceftriaxone, on avait d'abord isolé $C$ trachomatis après le traitement. Lorsque tous les types d'échecs thérapeutiques microbiologiques et cliniques ont été inclus, le résultat s'est révélé nettement meilleur avec la tétracycline $(\mathrm{P}<0,001)$. Le traitement optimal des patients atteints de gonorrhée doit inclure des schémas thérapeutiques qui soient efficaces à la fois contre $C$ trachomatis et $N$ gonorrhoeae.

Divisions of Infectious Disease and Medical Microbiology, Faculty of Medicine, University of British Columbia; and the Division of Venereal Disease Control and the British Columbia Centre for Disease Control, Ministry of Health, British Columbia

Correspondence: Dr WR Bowie, Division of Infectious Diseases, GF Strong Research Laboratories, Room 452, D floor,

2733 Heather Street, Vancouver, British Columbia V5Z 3J5. Telephone (604) 875-4147, Fax (604) 875-4013

Received for publication January 8, 1991. Accepted February 12, 1992 
A LTHOUGH THE OVERALL FREQUENCY OF GONOCOCCAL infections in Canada is decreasing, the prevalence of isolates resistant to penicillins and tetracyclines is increasing $(1,2)$. This has resulted in the need for treatment with alternative antimicrobials active against Neisseria gonorrhoeae as is reflected in the 1988 Canadian guidelines as well as both recent and older American guidelines (3-5). These guidelines have also stressed the importance of treating gonococcal infection with regimens active against both $N$ gonorrhoeae and Chlamydia trachomatis. Among patients with gonorrhea or contact to gonorrhea, approximately 20 to $30 \%$ of heterosexual men and 40 to $50 \%$ of women (6) are co-infected with $\mathrm{C}$ trachomatis, and focusing treatment only on $N$ gonorrhoeae often fails to manage adequately the whole patient. Single dose regimens usually fail to eradicate $C$ trachomatis and leave patients at risk not only for more trivial problems like post gonococcal urethritis and post gonococcal proctitis, but also more significant sequelae like endometritis and salpingitis $(7,8)$.

Recent Canadian data indicate that treatment for gonorrhea directed against both $N$ gonorrhoeae and $C$ trachomatis is still not being used regularly (2). A study conducted in Vancouver from 1982 to 1984 clearly showed the importance of treating both infections in patients with gonorrhea. It also demonstrated the usefulness of ceftriaxone, which has emerged as a mainstay of treatment for $N$ gonorrhoeae. At the time the study was performed, penicillinase-producing $N$ gonorrhoeae (PPNG) were infrequent, but chromosomally mediated resistance to $N$ gonorrhoeae (CMRNG) was more frequent (9). High level tetracycline resistance was not documented in British Columbia (or anywhere in Canada) until 1986 (10).

The objective of our study was to evaluate in a Canadian centre three treatment regimens for patients with gonorrhea in terms of the total clinical and microbiological outcome, rather than just the microbiological outcome for $N$ gonorrhoeae. Results are presented for tetracycline $500 \mathrm{mg}$ orally four times daily for five days (as a regimen which at that time was likely to be active against both $N$ gonorrhoeae and $C$ trachomatis), and for ceftriaxone $250 \mathrm{mg}$ intramuscularly (a regimen likely to be totally active against $N$ gonorrhoeae but without activity against $C$ trachomatis [1 1]).

\section{METHODS}

Study participants were drawn from consecutive men and women who presented to the Vancouver Sexually Transmitted Disease Clinic in the Provincial Health Building from June 1982 to June 1984 with gonorrhea or a history of contact to gonorrhea. Patients were eligible for the study if they were willing to cooperate with follow-up, were not allergic to antimicrobials used in the study, were not pregnant, had not missed their last period, and had not taken antimicrobials in the preceding two weeks.
A standard sexual history and genital examination were performed. Urethral specimens from heterosexual men, and urethral and rectal specimens from homosexual or bisexual men, were obtained for culture for $N$ gonorrhoeae and $C$ trachomatis. Cervical, urethral, and rectal cultures for $N$ gonorrhoeae and cervical and urethral cultures for $C$ trachomatis were obtained from all women, and rectal cultures for $C$ trachomatis were obtained from the last 53 women. Pharyngeal cultures for $N$ gonorrhoeae were obtained if indicated. The swab for taking $C$ trachomatis urethral specimens from men was inserted 3 to $4 \mathrm{~cm}$. Endourethral specimens from men, and vaginal swabs from women, were obtained for culture for Ureaplasma urealyticum. After obtaining urethral specimens, the first $10 \mathrm{~mL}$ of urine were obtained from men to detect trichomonads and to quantitate pyuria. Serum was obtained from all individuals for syphilis serology.

Patients with specimens showing Gram-negative intracellular diplococci on initial smears, those whose cultures were known to be positive for $N$ gonorrhoeae, or those with a history of known or possible contact to a patient with gonorrhea were then randomized to receive treatment according to a computer-generated randomization schedule. The regimens were: oral tetracycline 500 mg qid for five days; oral trimethoprim-sulfamethoxazole (TMP-SMX) nine tablets (720 mg/3600 $\mathrm{mg}$ ) once daily for three days; and ceftriaxone $250 \mathrm{mg}$ given intramuscularly with $2 \mathrm{~mL}$ of $1 \%$ xylocaine without adrenaline. Ceftriaxone was included in the randomization schedule after it was approved for use by the Health Protection Branch in January 1993. Treatment was not blinded. Since TMP-SMX is no longer considered a therapeutic option for treatment of gonorrhea, the results with TMP-SMX are not provided here.

An attempt was made to see all treated individuals five to seven days after cessation of treatment. Those whose initial cultures were positive for either $N$ gonorrhoeae or $C$ trachomatis were requested to return two, four, and six weeks after cessation of treatment. Men were requested to return for follow-up evaluations without having voided for four or more hours. With the exception of the syphilis serology, all studies performed initially were repeated on each follow-up visit. Where possible, patients were re-treated only under the following conditions: follow-up diagnostic tests were positive; symptomatic proctitis was present; or there was persistent or recurrent urethritis associated with all three of: symptoms, urethral discharge, and increased numbers of polymorphonuclear leukocytes on smear or in the first voided urine.

Laboratory diagnosis was by standard methods (1214). On smear, the significant number of polymorphonuclear leukocytes was defined as a mean of four or more per field in five $1000 x$ oil fields in a Gram stain of the urethral smear. In urine, the significant number was defined as 15 or more polymorphonuclear leuko- 
TABLE 1

Initial isolation of $N$ gonorrhoeae, $C$ trachomatis and $U$ urealyticum according to sexual preference

\begin{tabular}{|c|c|c|c|c|c|c|c|c|}
\hline \multirow[b]{2}{*}{ Sex } & \multirow[b]{2}{*}{$\begin{array}{l}\text { Sexual } \\
\text { preference }\end{array}$} & \multicolumn{7}{|c|}{ Number $(\%)$} \\
\hline & & Total & $\mathrm{C}+\mathrm{N}+$ & $\mathrm{C}-\mathrm{N}+$ & $\mathrm{C}+\mathrm{N}-$ & $\mathrm{C}-\mathrm{N}-$ & $U_{+}$ & $\begin{array}{c}(\%) \\
\mathrm{C}+\mathrm{N}+/ \mathrm{N}+\end{array}$ \\
\hline Female & Heterosexual & 109 & $34(31)$ & $42(39)$ & $11(10)$ & $22(20)$ & $101(93)$ & 44 \\
\hline Male & Bisexual & 44 & $3(7)$ & $34(77)$ & - & $7(16)$ & $11(25)$ & 8 \\
\hline Male & Homosexual & 146 & $14(10)$ & $112(77)$ & $2(1)$ & $18(12)$ & $37(25)$ & 11 \\
\hline
\end{tabular}

$\mathrm{C}+\mathrm{N}+\mathrm{C}$ trachomatis and $\mathrm{N}$ gonorrhoeae both identified; $\mathrm{C}-\mathrm{N}+$ Only $\mathrm{N}$ gonorrhoeae identified; $\mathrm{C}+\mathrm{N}-$ Only $\mathrm{C}$ trachomatis identified; $\mathrm{C}-\mathrm{N}-\mathrm{Neither}$ $\mathrm{C}$ trachomatis nor $\mathrm{N}$ gonorrhoeae identified; $\mathrm{U}+\mathrm{U}$ urealyticum isolated

cytes in two or more of five random $400 x$ fields in the sediment of the first voided urine (15).

Analysis of outcome: Five types of failure were defined: persistence or recurrence of $N$ gonorrhoeae or $\mathrm{C}$ trachomatis in patients from whom these organisms were initially detected; new isolation of $C$ trachomatis in patients from whom it was not initially detected; persistent urethritis in men where there was minimal or no response to treatment but cultures were negative for $N$ gonorrhoeae and $C$ trachomatis soon after treatment; post gonococcal urethritis in men, 14 or more days after treatment (increased number of polymorphonuclear leukocytes plus symptoms of urethritis, plus urethral discharge, but excluding those with positive cultures for C trachomatis); and post gonococcal proctitis (rectal symptoms and an increased number of polymorphonuclear leukocytes on rectal smears, but negative cultures for $N$ gonorrhoeae and $C$ trachomatis) 14 or more days post treatment.

For patients who initially had positive cultures for $N$ gonorrhoeae or $C$ trachomatis, and had positive cultures after treatment, it was considered to be a definite microbiological failure when patients denied having sexual intercourse, had sexual intercourse but used a condom, or had sexual intercourse only with a partner who was known to be treated adequately. Additionally for $N$ gonorrhoeae, to be considered a microbiological failure, the in vitro susceptibility of the isolate at the time of failure was similar to the initial isolate.

Fisher's exact test (fewer than 60 patients) (16) or $\chi^{2}$ analysis with Yates' correction (more than 60 patients) (17) were used for statistical comparisons.

The protocol was approved by the Human Subjects Review Committee of the University of British Columbia. All patients gave written informed consent.

\section{RESULTS}

Initial isolation results: A total of 109 women and 412 men were enrolled in the study. The number of patients identified initially with $C$ trachomatis, $N$ gonorrhoeae, and $U$ urealyticum are shown according to sex and sexual preference in Table 1. All C trachomatis isolates from heterosexual and bisexual men were from the urethra, while nine of $16(56 \%)$ isolates from homosexual men were from the rectum. Overall rates of detection of $C$ trachomatis were not significantly different between men with different sexual preferences, although urethral $C$ trachomatis infection was significantly less frequent in homosexual compared with heterosexual men $(\mathrm{P}<0.001)$. Eighteen women had positive cultures for $C$ trachomatis from both the cervix and urethra, 23 from the cervix alone, two from the urethra alone, and two from the cervix, urethra, and rectum. Uurealyticum was isolated from 18 of 56 men (32\%) with $N$ gonorrhoeae and $C$ trachomatis; 79 of 317 men (25\%) with $N$ gonorrhoeae alone; three of four men with $C$ trachomatis alone; and 18 of 35 men (51\%) with neither $N$ gonorrhoeae nor $C$ trachomatis (not shown in Table 1). The difference in overall rates of isolation of $U$ urealyticum between men with $N$ gonorrhoeae alone and men with neither $N$ gonorrhoeae nor $C$ trachomatis was statistically significant $(\mathrm{P}<0.025)$.

Microbiological outcome for $\boldsymbol{N}$ gonorrhoeae treatment: There were no statistically significant differences between treatment groups with respect to age, sex, sexual preference, or initial microbiology. Unless stopped because of side effects, patients were thought to have taken their medications (according to patient diaries and questioning). In total, 387 of the 449 individuals $(86.2 \%)$ initially shown to have $N$ gonorrhoeae made one or more follow-up visits, six or more days after cessation of treatment. Rates of follow-up were similar on both regimens. All women were cured (27 on tetracycline, eight on ceftriaxone). The treatment results for $N$ gonorrhoeae in men are shown in Table 2 for all who were culture positive initially and were followed six or more days after cessation of treatment. For men, ceftriaxone always succeeded (58 urethra, 21 rectal, and two pharyngeal infections), and tetracycline succeeded in 142 of 148 men (with failures in two of 109 urethral, four of $15 \mathrm{rectal}$, and zero of seven pharyngeal infections).

Microbiological outcome for $C$ trachomatis infections: Of the 105 individuals with $C$ trachomatis infection diagnosed initially, $83(79 \%)$ made one or more follow-up visits 20 or more days after cessation of treatment. The microbiological treatment results for $C$ trachomatis are shown in Table 2 for all men initially infected with $C$ trachomatis and followed 21 or more days after cessation of treatment. Definite microbiologi- 
TABLE 2

Overall outcome in men with $N$ gonorrhoeae infection according to treatment regimens, excluding re-exposed failures

\begin{tabular}{lcc}
\hline & \multicolumn{2}{c}{ Regimen } \\
Outcome & $\mathrm{n}=121$ & $\mathrm{n}=77$ \\
\hline Microbiological failure & & \\
$\quad$ N gonorrhoeae & $6 / 121(5 \%)$ & $0 / 77$ \\
C trachomatis & $0 / 16$ & $8 / 10(80 \%)^{*}$ \\
Additional C trachomatis & $0 / 105$ & $12 / 67(18 \%)^{*}$ \\
positive & & $1(1 \%)$ \\
Persistent urethritis & 0 & $2(3 \%)$ \\
Post gonococcal urethritis & $2(2 \%)$ & $1(1 \%)$ \\
Post gonococcal proctitis & 0 & $24(31 \%)^{*}$ \\
Total poor outcome & $8(7 \%)$ & \\
\hline P<0.001 & &
\end{tabular}

cal failure occurred in no patients on tetracycline (11 women and $16 \mathrm{men}$ ) and $83 \%$ on ceftriaxone (two of two women and eight of 10 men) $(\mathrm{P}<0.001)$. Furthermore, an additional 13 individuals who received ceftriaxone and had negative cultures for $C$ trachomatis initially had positive cultures for $C$ trachomatis at the first follow-up visit. One other patient who received ceftriaxone developed positive cultures for $C$ trachomatis at the second follow-up after treatment.

Clinical outcome in women: One woman who had received ceftriaxone developed adnexal tenderness at follow-up. She had positive cultures for $C$ trachomatis at follow-up.

Outcome in men initially infected with $N$ gonorrhoeae: There was a poor outcome in $7 \%$ of men on tetracycline and $31 \%$ of men on ceftriaxone $(\mathrm{P}<0.001)$ (Table 2). If microbiological or clinical failures that arose in men who may have been reinfected are included, the rates of failure rose to 12 of 123 on tetracycline (10\%) and 30 of 77 on ceftriaxone $(39 \%)(\mathrm{P}<0.001)$.

Side effects: Information about side effects was obtained from a daily diary filled in by the patient and by questioning. Patients were not specifically asked about a list of side effects. In 181 tetracycline and 90 ceftriaxone courses, side effects of any kind were noted in $49 \%$ and $43 \%$, respectively. All were minor except for two individuals on tetracycline who stopped treatment because of side effects. Abdominal symptoms were most frequent on tetracycline $(38 \%)$ and local discomfort on ceftriaxone $(32 \%)$.

\section{DISCUSSION}

This study clearly shows that for best management of individuals with gonorrhea or contact to gonorrhea, treatment regimens must be active in vivo against not only $N$ gonorrhoeae, but also $C$ trachomatis and, to a lesser extent, $U$ urealyticum.

When this study was initiated, the suggested tetracycline regimen for treatment of gonorrhea had been
$500 \mathrm{mg}$ four times daily for five days. We continued the regimen since our results were more than satisfactory for all but rectal gonorrhea in men. However, we concur with the currently recommended seven day regimen. It should again be stressed that tetracyclines alone would no longer be expected to have similar efficacy against infection with $N$ gonorrhoeae because of increasing resistance, but the need for combination therapy remains. Despite studies such as this one, and the existence of Canadian and American guidelines strongly promoting the use of combination treatment in patients with proven or suspect gonococcal infection (3-5), combination treatments are not being used routinely in Canada (2). A large cross-Canada study that, if anything, would have been biased towards obtaining data from centres more likely to use recommended regimens, still reported frequent therapy directed only against $N$ gonorrhoeae (2). Typically the portion of therapy for $N$ gonorrhoeae was a penicillin. Penicillins are not the most appropriate choice in many parts of Canada $(1,2,18)$. Ceftriaxone is the currently recommended choice in these areas. In our study, as in others (11), ceftriaxone was highly effective against $N$ gonorrhoeae.

In addition to the conclusion that use of regimens that eradicate both $N$ gonorrhoeae and $C$ trachomatis are clinically desirable, there are also practical reasons for choosing a regimen with activity against both pathogens, and against $U$ urealyticum if feasible. Three reasons are very important. First, diagnostic facilities for C trachomatis that provide rapid results are not available to all practitioners. Diagnosis of gonorrhea or history of contact to gonorrhea indicates a significant likelihood of the presence of $C$ trachomatis, as has been shown again in this study. Second, as was seen in this study, concurrent $C$ trachomatis infection may not be detected at the time of initial evaluation, even using cultures. Many of our culture-positive patients were initially recognized at the first follow-up visit. This presumably is related to the slower replication of $C$ trachomatis compared with $N$ gonorrhoeae, resulting in a longer interval after exposure before the $C$ trachomatis replicates sufficiently to be recognized in diagnostic tests. Finally, diagnosis of $C$ trachomatis infection at follow-up by clinical criteria can be exceedingly difficult. Thus, many men with $C$ trachomatis lack an increase in the number of polymorphonuclear leukocytes in urethral material. Only three of 25 men who had positive urethral cultures for $C$ trachomatis at follow-up had increased polymorphonuclear leukocytes plus symptoms plus urethral discharge at the first follow-up visit with a positive culture for $\mathrm{C}$ trachomatis. Nevertheless, increased polymorphonuclear leukocytes at follow-up were frequent in men without $C$ trachomatis or $N$ gonorrhoeae being detected (data not shown). For all these reasons, initial use of a regimen with activity against both $N$ gonorrhoeae and $C$ trachomatis has practical advantages. Some might argue that it 
might not be necessary for homosexual men since the rate of urethral $C$ trachomatis infection is usually less in homosexual men with gonorrhea, as was found in this and other studies (6). Nevertheless, because $6 \%$ of the homosexual men in this study had rectal $C$ trachomatis infection, the overall prevalence of $C$ trachomatis in homosexual men with gonorrhea was not significantly different from heterosexual men.

Thus there are numerous reasons why treatment of gonorrhea should include a regimen with complete in vivo activity against both $N$ gonorrhoeae and $C$ trachomatis. The choice of regimens will vary with time, but the need for dual activity will not.

ACKNOWLEDGEMENTS: The assistance of Helen Nesbit, RN, Rae Archer, RN, Pat Lauener, BSN, Shannon Lawson, RN, Edgar Paulse, RN, Andrea Barber, BSN, Alex Tayob, RPN, Vincent Carballo, RPN, Jinny Rush, BSN, and the remainder of the staff of the Division of Venereal Disease Control is gratefully acknowledged. The research was funded by the National Health Research and Development Program, a Medical Research Council of Canada Development Grant, and Hoffmann-LaRoche Limited. Trimethoprim-sulfamethoxazole was supplied by Burroughs Wellcome Inc.

\section{REFERENCES}

1. Notifiable Diseases Annual Summary 1988. Ottawa: Laboratory Centre for Disease Control, Health and Welfare Canada.

2. Dillon JR, Hickey S, Drixler C, Carballo M, Pauzé M and the National Cooperative Study Group. National surveillance of Neisseria gonorrhoeae in Canada: Antimicrobial susceptibility, epidemiological typing and treatment. 8th Meeting of the International Society for Sexually Transmitted Diseases Research, Copenhagen. September 10 to $13,1989$.

3. MacDonald N, Bowie WR, Read S, eds. 1988 Canadian guidelines for the treatment of sexually transmitted diseases in neonates, children, adolescents, and adults. Can Dis Wkly Rep 1988 (April):14S2.

4. Centers for Disease Control. 1985 STD treatment guidelines. MMWR 1985;34(4SS):75S-108S.

5. Centers for Disease Control. 1989 Sexually Transmitted
Diseases treatment guidelines. MMWR 1989;38(S-8):v-43.

6. Bowie WR, Holmes K. Chlamydia trachomatis (trachoma, perinatal infections, lymphogranuloma venereum, and other genital infections). In: Mandell GL, Douglas RG, Bennett JE, eds. Principles and Practice of Infectious Diseases, 3rd edn. New York: Churchill Livingstone, 1989: 1426-40.

7. Stamm WE, Guinan ME, Johnson C, Starcher T, Holes K, McCormack WM. Effect of treatment regimens for Neisseria gonorrhoeae on simultaneous infection with Chlamydia trachomatis. N Engl J Med 1984;310:545-9.

8. Rees $\mathrm{E}$. The treatment of pelvic inflammatory disease. Am J Obstet Gynecol 1980;138:1042-7.

9. Bowie WR, Shaw CE, Chan DGW, Jones HD, Black WA. In-vitro susceptibility of 400 isolates of Neisseria gonorrhoeae in Vancouver, 1982-84. Can Med Assoc J 1986; 135:489-93.

10. Shaw CE, Chan DGW, Byrne SK, Black WA, Bowie WR. Tetracycline-resistant Neisseria gonorthoeae (TRNG)British Columbia. Can Dis Wkly Rep 1986;12:101.

11. Moran JS, Zenilman JM. Therapy for gonococcal infections: Options in 1989. Rev Infect Dis 1990;12 (Suppl 6):S633-44.

12. Ripa KT, Mardh PA. New simplified culture technique for Chlamydia trachomatis. In: Holes K; Hobson D, eds. Nongonococcal Urethritis and Related Infections. Washington: American Society for Microbiology. 1977:323-7.

13. Shepard MC, Lunceford CD. Differential agar medium (A7) for identification of Ureaplasma urealyticum (human $\mathrm{T}$ mycoplasmas) in primary cultures of clinical material. J Clin Microbiol 1976;3:613-25.

14. Shepard MC, Lunceford CD. Urease color test medium U-9 for the detection and identification of “T"-mycoplasmas in clinical material. Appl Microbiol 1970;20:539-43.

15. Bowie WR. Comparison of Gram stain and first-voided urine sediment in the diagnosis of urethritis. Sex Transm Dis $1978 ; 5: 39-42$.

16. Significance limits for the fourfold table test. In: Deim K, ed. Scientific Tables, 6th edn. Ardsley: Geigy Pharmaceuticals, 1962:113-23.

17. Colton T. Statistics in Medicine. Boston: Little Brown and Co, 1974:174-7.

18. Rekart ML. Penicillinase-producing Neisseria gonorrhoeae (PPNG) in British Columbia. Can Dis Wkly Rep 1990; 16:245-6. 


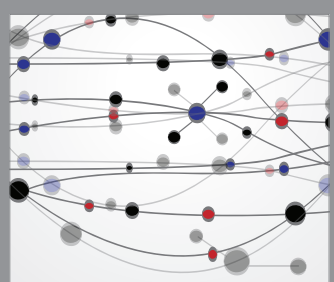

The Scientific World Journal
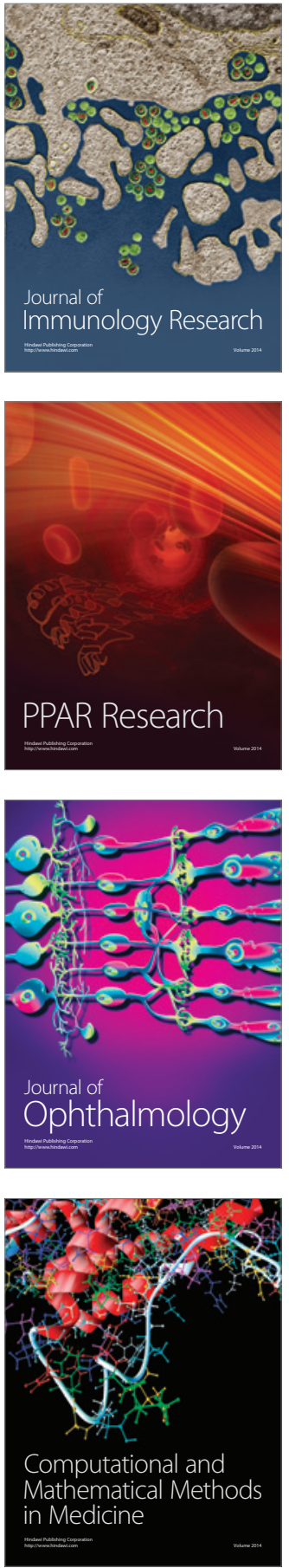

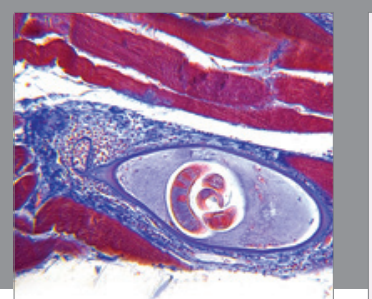

Gastroenterology Research and Practice

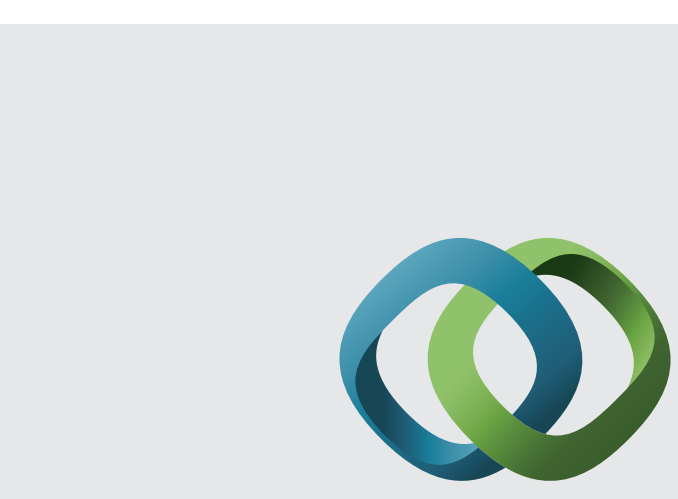

\section{Hindawi}

Submit your manuscripts at

http://www.hindawi.com
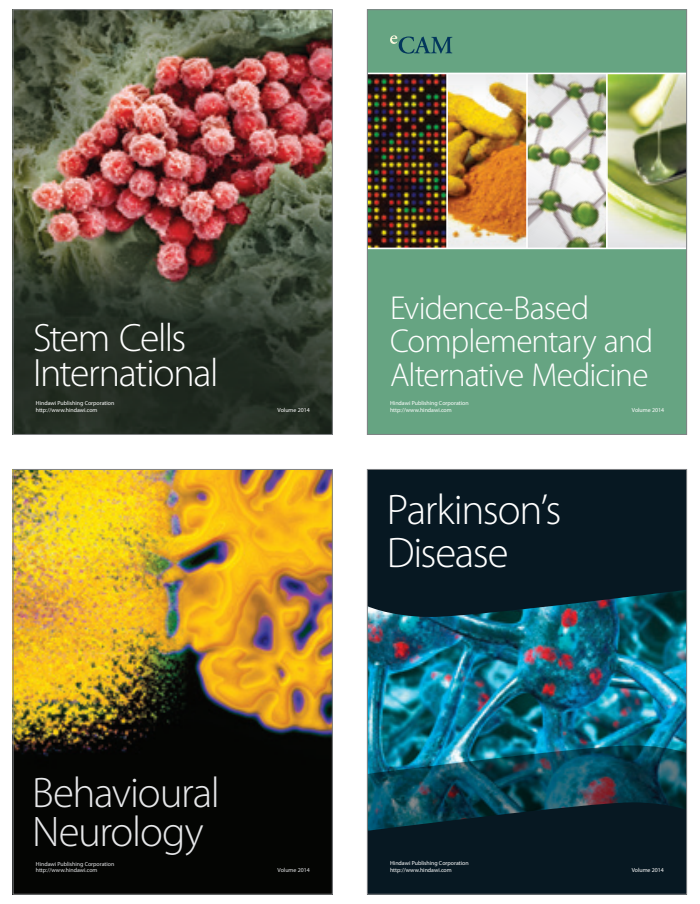
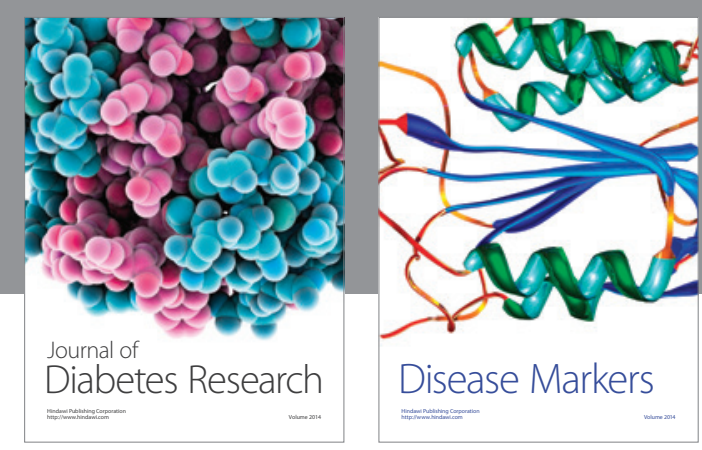

Disease Markers
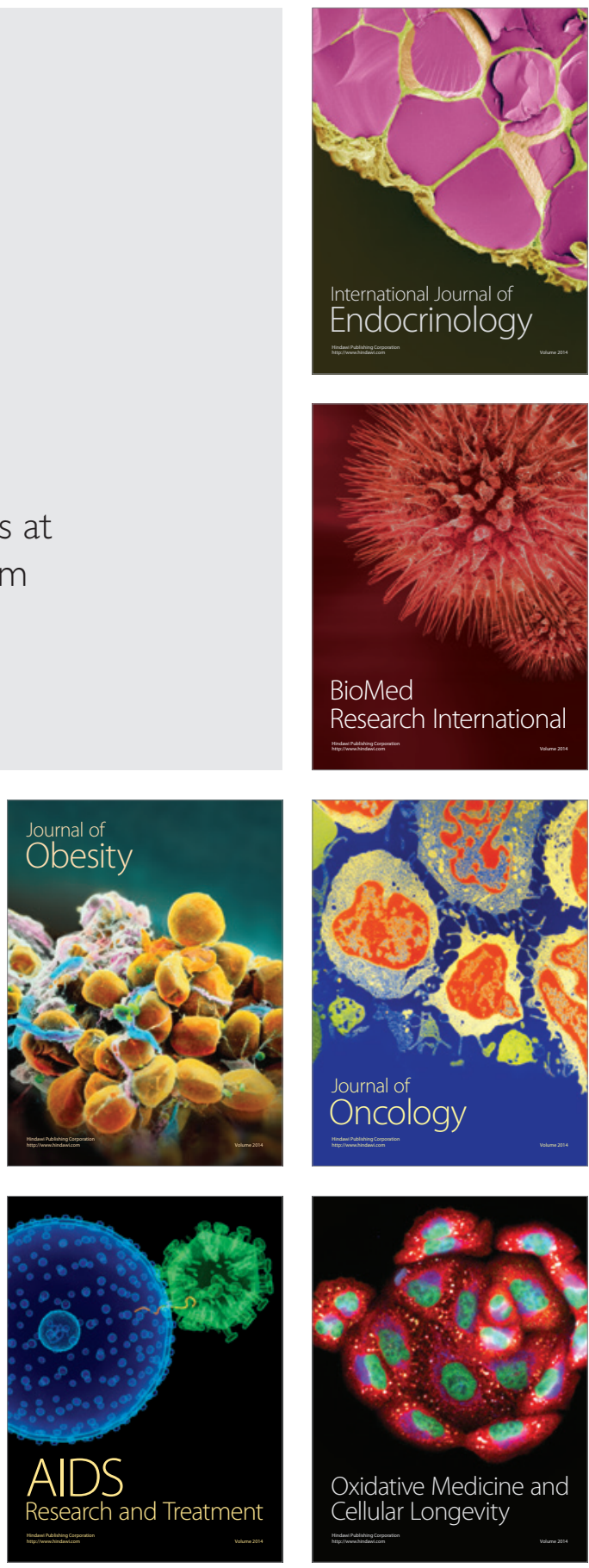